\title{
Metabolismo fotossintético de variedades de palma forrageira cultivadas no Semiárido brasileiro
}

\author{
Photosynthetic metabolism of cultivated forage palm varieties \\ in the Brazilian semiarid
}

Instituto Agronômico de Pernambuco (IPA), Av. General San Martin, 1371. Bongi, CEP 50761-000, Recife, PE, Brasil

* autor correspondente \abel.alves@ipa.br

Francisco Abel Lemos Alves ${ }^{1 *}$, Djalma Cordeiro dos Santos ${ }^{1}$, Sérvulo Mercier Siqueira e Silva ${ }^{1}$, Maria da Conceição Silva' ${ }^{1}$, Daniela Rosário de Mello

RESUMO: O objetivo desta pesquisa foi caracterizar fisiologicamente, dentro de um grupo fotossintético, as principais variedades de palma forrageira cultivadas no Brasil. O estudo foi conduzido nas estações experimentais do IPA localizadas nos municípios pernambucanos de Ibimirim e Arcoverde. Utilizou-se o delineamento de blocos casualizados em Ibimirim (experimento de campo) e inteiramente casualizado em Arcoverde (experimento realizado em um telado), cada um com três repetições, sendo os tratamentos experimentais representados pela combinação de quatro variedades de palma forrageira (IPA-200016, IPA-100003, IPA-200205 e IPA-100004), duas condições de cultivo (sequeiro e irrigada/complementação hídrica) e três horários de avaliação (7, 9 e 14 horas). A complementação hídrica correspondeu a 1/3 da evapotranspiração total semanal. Nas avaliações foram realizadas as seguintes medidas: temperatura do ar ambiente - $T_{\text {air }}$, temperatura dos cladódios - $T_{\text {leap }}$ radiação fotossintética ativa - $P A R$, déficit de pressão de vapor - $V P D$, taxa de assimilação líquida de $\mathrm{CO}_{2}-P n$, taxa de transpiração - $E$, condutância estomática $-C$, concentração interna de $\mathrm{CO}_{2}-\mathrm{CO}_{2 i n t}$ e umidade dentro - Rhin e fora - RHout da câmara estomática. Essas medidas foram determinadas em todos os cladódios das plantas no período de agosto a dezembro de 2018 às 7,9 e 14 horas. Constatou-se variação para $T_{\text {air, }}, T_{\text {leap }} V P D, P n, E, C$ e $C O_{2 i n t .}$ entre os horários de avaliação. As maiores $T_{\text {air }}, T_{\text {leap }} V P D$, $C$ e $C O_{\text {2int. }}$ foram obtidas à tarde, provavelmente pelo aumento da radiação solar, enquanto as maiores $P n$ e $E$ foram obtidas pela manhã. Diante desses resultados, e considerando que, nas espécies de Opuntia e Nopalea, as maiores taxas de assimilação líquida de $\mathrm{CO}_{2}$ ocorrem à noite (modo CAM), a constatação de trocas gasosas durante o dia possibilita caracterizar as principais variedades de palma forrageira cultivadas no Brasil como plantas do grupo fotossintético CAM-facultativo.

PALAVRAS-CHAVE: Cactáceas, CAM-facultativo, carboxilação, irrigação, Nopalea, Opuntia.
ABSTRACT: The objective of this research was to characterize physiologically, within a photosynthetic group, the main varieties of forage palm cultivated in Brazil. The study was conducted at the IPA Experimental Stations, located in the Pernambuco municipalities of Ibimirim and Arcoverde. A randomized block design was used in Ibimirim (field experiment) and completely randomized in Arcoverde (experiment carried out in a greenhouse), each with three replications, with the experimental treatments represented by the combination of four varieties of forage palm (IPA-200016, IPA-100003, IPA-200205, and IPA-100004), two cultivation conditions (dryland and irrigated/water complementation) and three evaluation times (07:00 a.m., 09:00 a.m., and 02:00 p.m.). Water complementation corresponded to $1 / 3$ of the total weekly evapotranspiration. In the evaluations, the following measurements were taken: ambient air temperature - Tair, the temperature of the cladodes - Tleaf, active photosynthetic radiation - APR, vapor pressure deficit - VPD, net $\mathrm{CO}$, assimilation rate - Pn, transpiration rate - E, stomatal conductance - $\mathrm{C}$, internal $\mathrm{CO}_{2}$ concentration - $\mathrm{CO}_{2 \text { int. }}$ and humidity inside - Rhin and outside-RHout of the stomatal chamber. These measures were determined in all cladodes of plants from August to December 2018 at 07:00 a.m., 09:00 a.m., and 02:00 p.m. Variation was found for Tair, Tleaf, VPD, $P n, E, C$, and $C O_{2 \text { int }}$ between evaluation times. The largest Tair, Tleaf, VPD, C, and $\mathrm{CO}_{2 \text { int. }}$ were obtained in the afternoon, probably due to the increase in solar radiation, while the highest Pn and E were obtained in the morning. Because of these results, and considering that in the species of Opuntia and Nopalea, the highest rates of net $\mathrm{CO}_{2}$ assimilation occur at night (CAM mode), the observation of gas exchange during the day enables to characterize the main varieties of forage palm cultivated in Brazil as plants of the CAM-optional photosynthetic group.

KEYWORDS: Cacti, CAM-optional, carboxylation, irrigation, Nopalea, Opuntia. 


\section{Introdução}

O Semiárido do Brasil se caracteriza por apresentar elevadas temperaturas diurnas, alta radiação solar, baixa umidade do ar e baixa precipitação pluviométrica. Nessa região as chuvas, geralmente, são descontínuas, infrequentes, imprevisíveis e aleatórias, concentradas em poucos meses do ano, enquanto os solos em sua maioria são rasos e com baixa capacidade de armazenamento de água (ALVES et al., 2020).

Dessa forma, as características edafoclimáticas do Semiárido limitam o cultivo de plantas que não toleram déficit hídrico por longos períodos (ALVES et al., 2017). Todavia, espécies de Opuntia e Nopalea desenvolveram características anatômicas, morfológicas, fisiológicas e bioquímicas que permitem seu desenvolvimento nesses ambientes (OLIVEIRA et al., 2010). No Brasil, algumas dessas espécies são muito difundidas e utilizadas na alimentação animal, notadamente, no período seco do ano (ALVES et al., 2016), a exemplo das palmas forrageiras.

Estima-se que, aproximadamente, 147.439 ha do território nacional sejam cultivados com a Opuntia ficus-indica (cv. Gigante, Redonda e Clone IPA- 20), Opuntia stricta (cv. Orelha de Elefante Mexicana) e Nopalea cochenillifera (cv. Miúda e IPA-Sertânia), todas variedades de palma forrageira (INSTITUTO BRASILEIRO DE GEOGRAFIA E ESTATISTICA, 2017).

Apesar da palma ser uma cultura importante para a pecuária no Nordeste brasileiro, poucos foram os estudos realizados na área de fisiologia vegetal, principalmente em relação às trocas gasosas e fotossíntese (carboxilação) dessas cactáceas na região. A maioria dos resultados obtidos nestas áreas de estudo foram relacionados a $O$. ficus-indica, sem nenhuma referência as variedades cultivadas no Brasil.

Estudos preliminares realizados pelo IPA em condições controladas (telado e irrigação periódica) com algumas variedades de palma forrageira indicaram a existência de trocas gasosas (assimilação de $\mathrm{CO}_{2}$ e perda de $\mathrm{H}_{2} \mathrm{O}$ ) durante o período diurno (ALVES et al., 2018a,b).

Assim, o objetivo desta pesquisa foi caracterizar fisiologicamente, dentro de um grupo fotossintético, as principais variedades de palma forrageira cultivadas no Brasil.

\section{Material e Métodos}

Os experimentos foram conduzidos nas estações experimentais do Instituto Agronômico de Pernambuco (IPA), localizadas nos municípios pernambucanos de Ibimirim e Arcoverde, ambos pertencentes à região do Semiárido brasileiro.
Utilizou-se o delineamento de blocos casualizados em Ibimirim (experimento de campo) e inteiramente casualizado em Arcoverde (experimento realizado em um telado), cada um com três repetições, sendo os tratamentos experimentais representados pela combinação de quatro variedades de palma forrageira (IPA-200016, IPA-100003, IPA-200205 e IPA-100004), duas condições de cultivo (sequeiro e irrigada/complementação hídrica) e três horários de avaliação (7, 9 e 14 horas).

A cultivar IPA-200016 (Orelha de elefante mexicana-O.E.M.) é uma Opuntia. stricta, a IPA-100003 (Clone IPA-20) é Opuntia ficus-indica e as cultivares IPA-200205 (IPA-Sertânia) e IPA-100004 (Miúda) são Nopalea cochenillifera.

O solo de cultivo das plantas em condições de campo no município de Ibimirim-PE é classificado como Neossolo Flúvico Eutrófico, salino-sódico, com textura variando de franco a franco-arenosa, com condutividade elétrica do extrato de saturação $\left(17,0 \mathrm{dSm}^{-1}\right.$ a $\left.25^{\circ} \mathrm{C}\right)$, percentagem de sódio trocável $(32,4)$, teores de cálcio $\left(>10 \mathrm{cmol}_{\mathrm{c}} \mathrm{dm}^{-3}\right)$, fósforo $\left(>40 \mathrm{mg} \mathrm{dm}^{-3}\right)$ e potássio $\left(0,28 \mathrm{cmol}_{\mathrm{c}} \mathrm{dm}^{-3}\right)$ (LIRA-JÚNIOR et al., 2014; NUNES-FILHO et al., 2008). O solo do cultivo das plantas em telado no município de Arcoverde-PE é classificado como neossolo regolítico eutrófico solódico com fragipan, com predominância da fração areia grossa em todos os horizontes, percentagem de sódio trocável $(0,7$ à 6,3$)$, teores de cálcio $(2,2$ à $\left.4,6 \mathrm{cmol}_{\mathrm{c}} \mathrm{dm}^{-3}\right)$, magnésio $\left(1,1 \mathrm{à} 4,1 \mathrm{mg} \mathrm{dm}^{-3}\right)$, fósforo $(6,0$ à $\left.33,0 \mathrm{mg} \mathrm{dm}^{-3}\right)$ e potássio $\left(0,3\right.$ à $\left.0,5 \mathrm{cmol}_{\mathrm{c}} \mathrm{dm}^{-3}\right)$ (SOUSA et al., 2011). Na implantação dos experimentos e a cada ano, as plantas foram adubadas com 20 t.ha ${ }^{-1}$ de esterco bovino, aplicados ao solo, entre as fileiras.

Os clones "sementes" foram obtidos no Banco Ativo de Germoplasma - BAG de palma forrageira do IPA e o plantio da área no município de Ibimirim-PE foi realizado em dezembro de 2016, utilizando um cladódio por cova, no espaçamento de $1,50 \mathrm{~m}$ entre linhas e $0,40 \mathrm{~m}$ entre plantas dentro das linhas.

O plantio e cultivo das plantas no município de Arcoverde-PE aconteceu em telado com redução de luminosidade de 50\%, em novembro de 2015, usando um cladódio por cova no espaçamento $1,00 \mathrm{~m}$ entre linhas e $0,20 \mathrm{~m}$ entre plantas em uma área de $1,8 \mathrm{~m}^{2}$.

As áreas sob condições de sequeiro receberam água proveniente das chuvas, podendo os registros de precipitações pluviométricas locais serem observados na Tabela 1 , conforme os meses de 2016 a 2018. A complementação hídrica das plantas no telado correspondeu a $1 / 3$ da evapotranspiração total semanal, realizada por regadores de plástico com capacidade

Tabela 1. Precipitação pluviométrica mensal da área experimental nos anos de 2016 a 2018, localizada no município de Ibimirim-PE, Brasil.

\begin{tabular}{|c|c|c|c|c|c|c|c|c|c|c|c|c|}
\hline \multirow{2}{*}{ Anos } & \multicolumn{12}{|c|}{ Meses } \\
\hline & $\mathbf{J}$ & F & M & $\mathbf{A}$ & M & $\mathbf{J}$ & $\mathbf{J}$ & $\mathbf{A}$ & $\mathbf{S}$ & O & $\mathbf{N}$ & D \\
\hline 2016 & 114,3 & 107,7 & 19,0 & 0,0 & 109,3 & 2,7 & $\mathbf{0 , 0}$ & $\mathbf{0 , 0}$ & $\mathbf{0 , 0}$ & $\mathbf{0 , 0}$ & $\mathbf{0 , 0}$ & $\mathbf{0 , 0}$ \\
\hline 2017 & 2,5 & 20,5 & 107,3 & 18,0 & 59,1 & 41,8 & 33,5 & 22,4 & 6,3 & 0,0 & $\mathbf{0 , 0}$ & 49,2 \\
\hline 2018 & 11,9 & 131,0 & 136,6 & 173,2 & 13,0 & 0,8 & $4,2 *$ & $\mathbf{0 , 0}$ & $\mathbf{0 , 0}$ & 0,2 & $10,6^{* *}$ & $45,0 * * *$ \\
\hline
\end{tabular}

*dias com precipitação no mês de julho de $2018(07.07=3,0 \mathrm{~mm}$ e $24.07=1,2 \mathrm{~mm})$; **dias com precipitação no mês de novembro de $2018(27.11=8,0 \mathrm{~mm}$; $28.11=2,6 \mathrm{~mm}) ; * * *$ dias com precipitação no mês de dezembro de $2018(03.12=3,0 \mathrm{~mm} ; 05.12=4,0 \mathrm{~mm} ; 06.12=1,0 \mathrm{~mm} ; 10.12=5,5 \mathrm{~mm} ; 11.12=10,0 \mathrm{~mm}$; $18.12=18 \mathrm{~mm} ; 24.12=3,5 \mathrm{~mm})$. 
para 10 litros, em turnos de rega com intervalos de sete dias (ALVES et al., 2020).

No período de agosto a dezembro de 2018 foram determinadas as seguintes medidas: temperatura do ar ambiente $\left(T_{a i r}\right)$, temperatura dos cladódios $\left(T_{\text {leaf }}\right)$, radiação fotossintética ativa $(P A R)$, déficit de pressão de vapor (VPD), taxa de assimilação líquida de $\mathrm{CO}_{2}(P n)$, taxa de transpiração $(E)$, taxa de condutância estomática $(C)$, taxa de concentração interna de $\mathrm{CO}_{2}\left(\mathrm{CO}_{2 \text { int. }}\right)$ e umidade dentro (Rhin) e fora (RHout) da câmara estomática, no período diurno. De forma específica, essas medições foram realizadas instantaneamente entre os dias 02 e 24/08/2018; 06, 07 e 08/11/2018 e 19/12/2018.

Nas avaliações realizadas, ainda foram consideradas as ordens de inserção dos cladódios sobre as medidas obtidas. Contudo, os resultados ficaram restritos às três primeiras ordens, pelo fato de as plantas só terem emitido cladódios até a terceira ordem.

O aparelho utilizado para determinação das medidas avaliadas foi o Sistema de Fotossíntese portátil Ultra-Light CI-340 ${ }^{\circledR}$, da CIDBio-Science. A câmara utilizada foi produzida pela CID Bio-Science especialmente para medição de cladódios de palma forrageira com área de observação de $14,70 \mathrm{~cm}^{2}$. O sistema utilizado no estudo foi o aberto, com taxa de fluxo de ar de 0,30 L.min ${ }^{-1}$, com pressão de $93,77 \mathrm{kPa}$ e taxa de fluxo de massa de $0,13 \mathrm{~mol} \cdot \mathrm{m}^{-2} \cdot \mathrm{s}^{-1}$.

A análise dos dados foi realizada determinando-se as médias e desvios padrão, através do programa Excel da Microsoft ${ }^{\circledR}$ Office 2010. Para a análise de variância e o teste de médias foi utilizado o programa Assistat ${ }^{\circledR}$ versão 5.6 (FERREIRA, 2019).

As equações utilizadas na determinação das medidas avaliadas estão descritas a seguir:

$$
W=\frac{V}{60} \times \frac{273.15}{T a} \times \frac{P}{1.013} \times \frac{1}{22.41} \times \frac{10000}{A}=2005.39 \times \frac{V \times P}{\operatorname{Ta} \times A}
$$

Sendo:

$W$ : taxa de fluxo de massa por área do cladódio $\left(\mathrm{mol} / \mathrm{m}^{2} / \mathrm{s}\right)$;

$V$ : taxa de fluxo de volume (litros/minuto);

Ta: temperatura do ar $(\mathrm{K})$;

$P$ : pressão atmosférica (bar);

$A$ : área do cladódio $\left(\mathrm{cm}^{2}\right)$;

60: conversão minutos para segundos;

22.41: volume de 1 (um) mol de qualquer gás a uma temperatura padrão de $273.15 \mathrm{~K}$ e uma pressão padrão de 1.013 bar (litros $/ \mathrm{mol})$;

10000: conversão $\mathrm{cm}^{2}$ para $\mathrm{m}^{2}$.

$P n=-W x(C 0-C i)=-2005.39 x \frac{V \times P}{\operatorname{Ta} \times A} x(C 0-C i)$

Sendo:

$P n$ : taxa de fotossíntese líquida $\left(\mu \mathrm{mol} / \mathrm{m}^{2} / \mathrm{s}\right)$;

$\mathrm{CO}(\mathrm{C} i)$ : concentração de $\mathrm{CO}_{2}$ saída (entrada) (ppm or $\mu \mathrm{mol} / \mathrm{mol}$ ).

$E=\frac{e 0-e i}{P-e 0} \times W \times 10^{3}$

$e 0=\frac{h r 0 x e s}{100}$

$e i=\frac{\text { hrixes }}{100}$ $e s=6.13753 \times 10^{-3} x e^{\operatorname{ta} x \frac{18.564-\frac{t a}{254.4}}{t a+255.57}}$

Sendo:

$E$ : taxa de transpiração $\left(\mathrm{mmol} / \mathrm{m}^{2} / \mathrm{s}\right)$; $e 0$ (ei): vapor de água saída (entrada) (bar);

$P$ : pressão atmosférica (bar);

es: vapor de água saturada à temperatura do ar (bar);

Ta: temperatura do ar $\left({ }^{\circ} \mathrm{C}\right)$;

hro (hri): umidade relativa saída (entrada) (\%).

$$
\begin{aligned}
& \text { Cleaf }=\frac{W}{\frac{\text { eleaf }-e 0}{e 0-e i} \times \frac{P-e 0}{P}-R b W} \times 1000 \\
& \text { eleaf }=6.13753 \times 10^{-3} \times e^{\text {Tleaf } x \frac{18.564-\frac{\text { Tleaf }}{254.4}}{\text { Tleaf }+255.57}}
\end{aligned}
$$

Sendo:

Cleaf: condutância estomática do cladódio $\left(\mathrm{mmol} / \mathrm{m}^{2} / \mathrm{s}\right)$; eleaf: vapor de água saturada à temperatura do cladódio (bar); Tleaf: temperatura do cladódio $\left({ }^{\circ} \mathrm{C}\right)$;

$R b$ : resistência da camada limite do cladódio $\left(\mathrm{m}^{2} \mathrm{~s} / \mathrm{mol}\right)$. $0.3 \mathrm{~m}^{2} \mathrm{~s} / \mathrm{mol}$ é usado.

CO2int. $=C i-1.6 \times P n(R b+$ Rleaf $)$

Sendo:

$\mathrm{CO}_{2}$ int: : $\mathrm{CO}_{2}$ interno (ppm or $\mu \mathrm{mol} / \mathrm{mol}$ );

Rleaf: resistência estomática do cladódio $\left(\mathrm{m}^{2} \mathrm{~s} / \mathrm{mol}\right)$.

\section{Resultados e Discusões}

No geral, as medidas de características ambientais (temperatura do ar ambiente - $T_{\text {air }}$, temperatura dos cladódios - $T_{\text {leaf }}$ e déficit de pressão de vapor - VPD) apresentaram diferenças significativas entre as variedades de palma forrageira, ordens dos cladódios dentro da variedade botânica e horários de avaliações diurnos (Tabelas 2 e 3; Figuras 1 e 2). A $T_{\text {air }}, T_{\text {leaf }}$ e $V P D$ foram maiores à tarde (Figura 1). Os cladódios secundários apresentam as maiores temperaturas e $V P D$, provavelmente por estarem mais expostos à radiação solar (Figura 2). Houve também diferença entre a $T_{\text {air }}$ e $T_{\text {leaf }}$ nos cladódios primários e secundários das palmas Orelha de elefante mexicana e Miúda. A $T_{\text {leaf }}$, por sua vez, se apresentou maior do que a $T_{\text {air }}$ nessas variedades (Figura 2).

As variedades Orelha de elefante mexicana e Clone IPA-20 apresentam as maiores $T_{\text {air }}, T_{\text {leaf }}$ e $V P D$ (Figuras 1 e 2). Essas plantas possuem área do cladódio idênticas e maiores em comparação às outras (ALVES et al., 2016), sendo mais eficientes na captação da radiação fotossintética ativa - $P A R$ (Figuras 1 e 2). $\mathrm{O}$ excesso de $P A R$ é convertido em energia, por isso o aumento da temperatura dos cladódios. Sob altas taxas de luminosidade, os cladódios precisam dissipar o excedente de energia absorvida para impedir danos ao aparelho fotossintético. Uma das estratégias para dissipar essa energia é a produção de calor (TAIZ et al., 2017).

As variedades de palma forrageira não apresentaram diferenças quanto às taxas de assimilação líquida de $\mathrm{CO}_{2}-P n$, de 
Tabela 2. Análise de variância das características ambientais e fisiológicas das variedades de palma forrageira Orelha de elefante mexicana - IPA-200016, Clone IPA-20 - IPA-100003 e Miúda - IPA-100004, cultivadas em condições de telado no município de Arcoverde-PE.

\begin{tabular}{|c|c|c|c|c|c|c|c|c|c|}
\hline \multirow{2}{*}{ Fonte de Variação } & \multicolumn{9}{|c|}{ Quadrado médio } \\
\hline & G.L & $\mathbf{T}_{\text {air }}$ & $\mathbf{T}_{\text {leaf }}$ & PAR & VPD & Pn & $\mathbf{E}$ & $\mathbf{C}$ & $\mathrm{CO}_{\text {2int. }}$ \\
\hline Bloco & 2 & 1,52 & 13,02 & 122763,59 & $\mathbf{0 , 3 3}$ & 0,11 & 0,017872 & 10,87 & 3916,13 \\
\hline Variedade & 2 & $12,37 * *$ & $23,83 * *$ & $86582,63 n s$ & $1,05 * *$ & $0,08 \mathrm{~ns}$ & $0,003339 \mathrm{~ns}$ & $0,66 n s$ & $4366,07 n s$ \\
\hline Horário & 1 & $259,61 * *$ & $433,16 * *$ & $5233,78 \mathrm{~ns}$ & $34,60 * *$ & $0,56 \mathrm{~ns}$ & $0,002606 * *$ & $403,84 * *$ & $866717,78 * *$ \\
\hline Variedades $\mathbf{x}$ horário & 2 & $0,61 \mathrm{~ns}$ & $0,95 \mathrm{~ns}$ & $31305,78 \mathrm{~ns}$ & $0,24 n s$ & $0,03 n s$ & $0,002606 n s$ & $0,66 n s$ & $4366,07 n s$ \\
\hline Resíduos & 10 & 0,19 & 1,30 & 60761,81 & 0,06 & 0,24 & 0,011672 & 6,22 & 10464,60 \\
\hline
\end{tabular}

G.L - grau de liberdade; $T_{\text {ai }}$ - temperatura do ar ambiente; $T_{\text {eaf }}$ - temperatura dos cladódios; PAR - radiação fotossintética ativa; VPD - déficit de pressão de vapor; Pn - taxa de assimilação líquida de $\mathrm{CO}_{2} ; \mathrm{E}$ - taxa de transpiração; $\mathrm{C}$ - taxa de condutância estomática; $\mathrm{CO}_{2 \text { int }}$ - taxa de concentração interna de $\mathrm{CO}_{2}$. ns não significativo.

*significativo a $5 \%$; **significativo a $1 \%$ pelo teste $\mathrm{F}$.

Tabela 3. Análise de variância das características ambientais e fisiológicas das variedades de palma forrageira Orelha de elefante mexicana - IPA-200016, IPA-Sertânia - IPA-200205 e Miúda - IPA-100004, cultivadas em condições de sequeiro, no município de Ibimirim-PE.

\begin{tabular}{|c|c|c|c|c|c|c|c|c|c|}
\hline \multirow{2}{*}{ Fonte de Variação } & \multicolumn{9}{|c|}{ Quadrado médio } \\
\hline & G.L & $\mathbf{T}_{\text {air }}$ & $\mathbf{T}_{\text {leaf }}$ & PAR & VPD & Pn & $\mathbf{E}$ & $\mathrm{C}$ & $\mathrm{CO}_{2 \text { int }}$ \\
\hline Bloco & 2 & 0,008472 & 2,31 & 54045,55 & 0,18 & 0,000017 & 0,001356 & 0,742022 & 4236,05 \\
\hline Variedade & 2 & $2,87 * *$ & $40,80 * *$ & $526879,52 * *$ & $2,49 * *$ & $0,025350 \mathrm{~ns}$ & $0,001756 *$ & $12632,87 * *$ & $268704,00 * *$ \\
\hline Ordem cladódio & 1 & $0,94 * *$ & $28,30 * *$ & $5,95 \mathrm{~ns}$ & $1,47 * *$ & 0,630939* & $0,000089 n s$ & $2852,39 * *$ & $251785,57 * *$ \\
\hline $\begin{array}{c}\text { Variedades x Ordem } \\
\text { cladódio }\end{array}$ & 2 & $1,58 * *$ & $10,15^{* *}$ & $74102,86 n s$ & $0,32 n s$ & $0,150206 n s$ & $0,000422 n s$ & $4149,41 * *$ & $233184,57 * *$ \\
\hline Resíduos & 10 & 0,11 & 1,50 & 21825,23 & 0,16 & 0,114437 & 0,000322 & 95,07 & 913,86 \\
\hline
\end{tabular}

G.L - grau de liberdade; $T_{\text {- }}$ - temperatura do ar ambiente; $T_{\text {eq }}$ - temperatura dos cladódios; PAR - radiação fotossintética ativa; VPD - déficit de pressão de vapor; Pn - taxa de assimilação líquida de $\mathrm{CO}_{2} ; \mathrm{E}$ - taxa de transpiração; $\mathrm{C}$ - taxa de condutância estomática; $\mathrm{CO}_{2 \text { int }}$ - taxa de concentração interna de $\mathrm{CO}_{2}$. ns não significativo. *significativo a $5 \% ; * *$ significativo a $1 \%$ pelo teste $\mathrm{F}$.
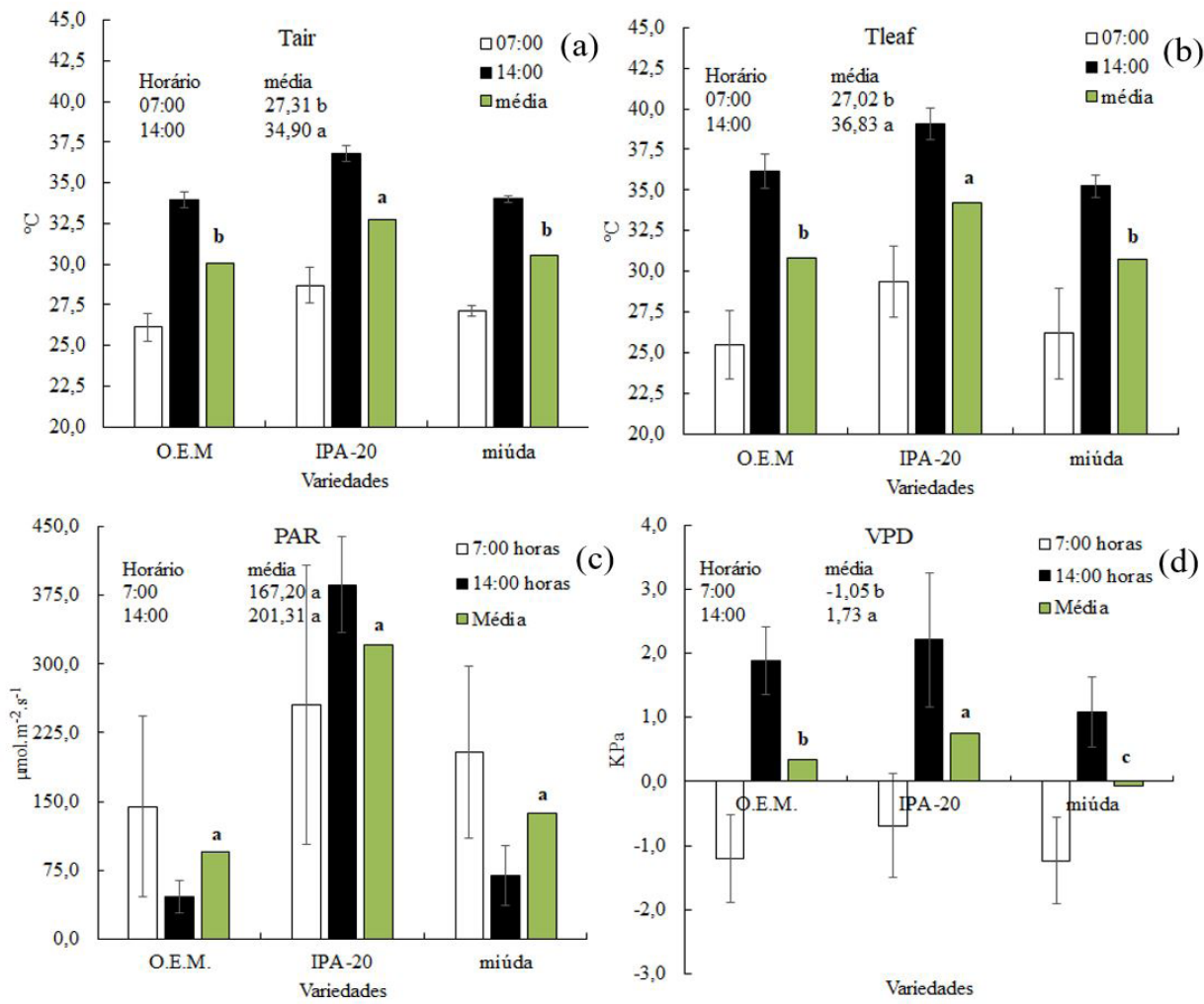

Figura 1. Temperatura diária do ar ambiente - $T_{\text {air }}$ (a) e dos cladódios - $T_{\text {leaf }}$ (b) às 7 horas e 14 horas, radiação fotossintética ativa - PAR (c) e déficit de pressão de vapor - VPD (d) nas variedades de palma forrageira Orelha de elefante mexicana - O.E.M. - IPA-200016, Clone IPA-20 - IPA-100003 e Miúda - IPA-100004, cultivadas em condições de telado, no município de Arcoverde-PE. As barras representam a média $(\mathrm{n}=6$ plantas $) \pm$ desvio padrão. Médias seguidas pela mesma letra não diferem entre si pelo teste de Tukey $(\mathrm{p}<0,05)$. 

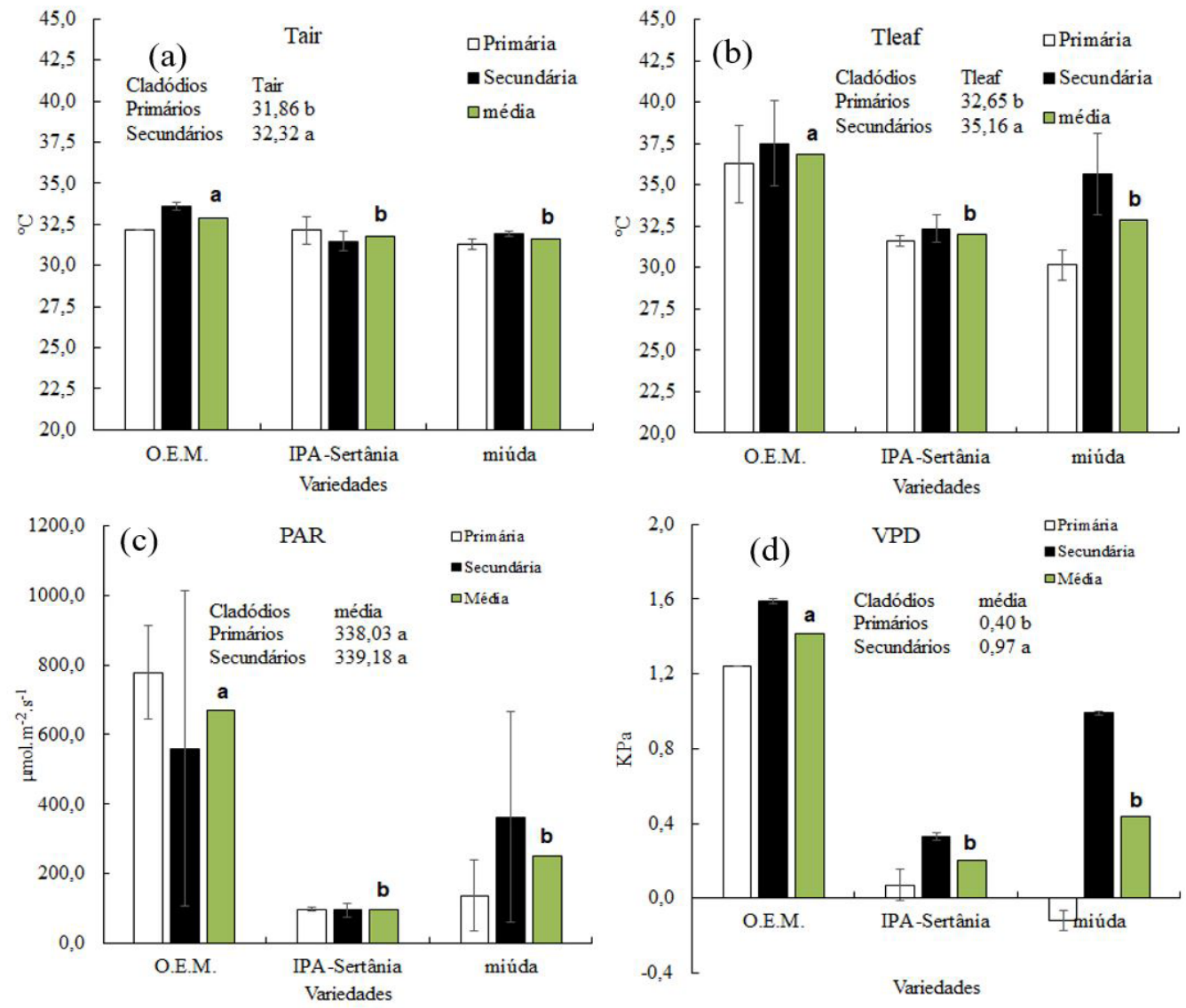

Figura 2. Temperatura diária do ar ambiente - $T_{\text {air }}$ (a) e dos cladódios - $T_{\text {leoff }}$ (b) primários e secundários, radiação fotossintética ativa - PAR (c) e déficit de pressão de vapor - $V P D$ (d) nas variedades de palma forrageira Orelha de elefante mexicana- O.E.M. - IPA-200016, IPA-Sertânia - IPA-200205 e Miúda - IPA-100004, cultivadas em condições de sequeiro, no município de Ibimirim-PE. As barras representam a média $(\mathrm{n}=6$ plantas $) \pm$ desvio padrão. Médias seguidas pela mesma letra não diferem entre si pelo teste de Tukey $(\mathrm{p}<0,05)$.

transpiração - $E$, de condutância estomática - $C$ e concentração interna de $\mathrm{CO}_{2}-\mathrm{CO}_{2 \text { int }}$ quando cultivadas no telado (Tabela 2 e Figura 3). No entanto, a $P n$ e $E$ são maiores pela manhã (7:00 horas), comparado à tarde (14:00 horas); e $C$ e $C O_{2 \text { int }}$ à tarde, comparado à manhã (Figura 3 ). Pela manhã a palma abre seus estômatos para realização das trocas gasosas, período que a temperatura está mais amena e o déficit de pressão de vapor é menor (RODRIGUES et al., 2011). No período da tarde ocorre um aumento na $C$ e $C O_{2 i n t}$ o qual é provocado pela descarboxilação do malato, respiração e pequena assimilação de $\mathrm{CO}_{2}$ pela abertura estomática (TAIZ et al., 2017).

As plantas cultivadas em um ambiente mais dinâmico (sob condições de campo) se apresentaram diferentes do ponto de vista fisiológico, quando comparadas àquelas cultivadas no telado (Tabela 3). Neste sentido, observou-se durante as avaliações diurnas realizadas que não houve diferença quanto à taxa de assimilação líquida de $\mathrm{CO}_{2}-P n$, mas a palma Miúda em comparação às outras variedades apresentou menor $C O_{2 \text { int }}$. Esse comportamento pode estar associado tanto a uma menor assimilação de $\mathrm{CO}_{2}$ pela palma Miúda no período noturno como a uma menor descarboxilação do malato no período diurno, como também por um metabolismo mais acelerado nesta variedade, o que resulta em menor $\mathrm{CO}_{2 \text { int }}$ (Figura 4).

Além do mais, os cladódios mais jovens (secundários) dessa variedade apresentaram maiores $C$ e $C O_{2 i n t}$ em comparação aos demais. No caso da palma IPA-Sertânia, esta apresentou maior concentração de $C$ nos cladódios primários. Resultados de pesquisas demonstram que a palma Miúda é mais exigente em água quando comparada às tradicionais cultivares de palma, o que significa dizer que, provavelmente, a palma Miúda sofre mais com o déficit hídrico. Neste contexto, segundo Taiz et al. (2017), plantas sob déficit hídrico reduzem a abertura estomática e, consequentemente, a transpiração e a concentração interna de $\mathrm{CO}_{2}$, principalmente nos cladódios mais velhos.

A $P n$ não variou entre as variedades de palma forrageira. No entanto, observa-se diferença entre as ordens dos cladódios. Os cladódios primários tendem apresentar maior taxa de assimilação de $\mathrm{CO}_{2}$ quando comparados aos secundários (Figura 4) provavelmente pelo fato de as estruturas fotossintéticas dos cladódios maduros estarem completamente desenvolvidas em comparação aos secundários. Além disso, observa-se um microclima formado dentro de uma planta, em que a temperatura do ar e a radiação solar são menos intensos e a umidade relativa do ar é maior na região onde são localizados os cladódios primários. Isso favorece uma maior $P n$ e menor $E$ nessa região da planta.

Os movimentos de abertura e fechamento estomáticos são influenciados, dentre outros fatores, pela temperatura do ar e do cladódio, intensidade de luz, concentração interna de $\mathrm{CO}_{2}$, umidade do ar, teor de água no solo, status hídrico e nutricional da planta e/ou cladódio, idade do cladódio e genótipo (BUCKLEY, 2017). 
A intensidade luminosa e as altas temperaturas influenciam a expressão gênica em plantas CAM-facultativas, que atuam no aumento da fluidez e permeabilidade do tonoplasto, aumentando o efluxo de ácidos orgânicos dos vacúolos para o citosol, elevando assim a $\mathrm{CO}_{2 \text { int }}$ que ficará disponível para a rubisco, por meio da descarboxilação (LUTTGE, 2004). Além do mais, a condutância estomática - $C$ está diretamente relacionada à abertura do estômato (tamanho) e envolve a evaporação da água que se encontra dentro dos órgãos fotossintéticos (cladódios), os quais se saturam de vapor de água. O déficit de saturação de vapor de água do ambiente aumenta exponencialmente com a temperatura, o qual ocasiona aumento na $C$ e, consequentemente, na transpiração e assimilação do $\mathrm{CO}_{2}$ (BUCKLEY, 2017).

Quando as plantas de palma forrageira Clone IPA-20 foram cultivadas em condições de telado na ausência e presença de complementação hídrica, a análise de variância dos resultados pelo teste $\mathrm{F}$ confirma a diferença significativa na $V P D, C$ e $C O_{2 i n t}$ entre as condições de cultivo (sequeiro e irrigado), os horários de avaliação (9:00 e 14:00 horas) e ordem do cladódio (broto e primário). Não foram observadas diferenças significativas entre a $P A R$ e $P n$ entre os horários de avaliação e condições de cultivo, na $E$ nas condições de cultivo e na $T_{\text {air }}$ e $T_{\text {leaf }}$ entre as ordens dos cladódios (Tabela 4).

$\mathrm{A} T_{\text {air }}, T_{\text {leaf }}$ e $V P D$ são maiores à tarde nas palmas cultivadas em condições de sequeiro (Tabela 5 e Figura 5). Isso era esperado, uma vez que a alta incidência de energia na terra à tarde, através da radiação solar, provoca aumento da radiação térmica dos corpos (GÓMEZ et al., 2018). A interdependência entre essas variáveis é bem estabelecida, uma vez que os maiores valores de déficit de vapor de água ou menor umidade do ar acontecem à tarde. A PAR é maior nos brotos (Tabela 5 e Figura 5), provavelmente por estes estarem posicionados de forma que favorece uma maior incidência da radiação solar.

A $C$ e $C O_{2 i n t}$ são maiores nos brotos e quando cultivadas em condições de sequeiro (Tabela 5). Os cladódios mais jovens provavelmente são menos eficientes no controle da perda de água - abertura e fechamento dos estômatos - em comparação aos cladódios maduros (DONATO; SILVA; DONATO, 2020). As plantas, quando bem hidratadas, permanecem com seus estômatos abertos durante o dia para captação de $\mathrm{CO}_{2}$ e perda de $\mathrm{H}_{2} \mathrm{O}$ no processo de dissipação do excesso de energia absorvido pela radiação solar e impedir
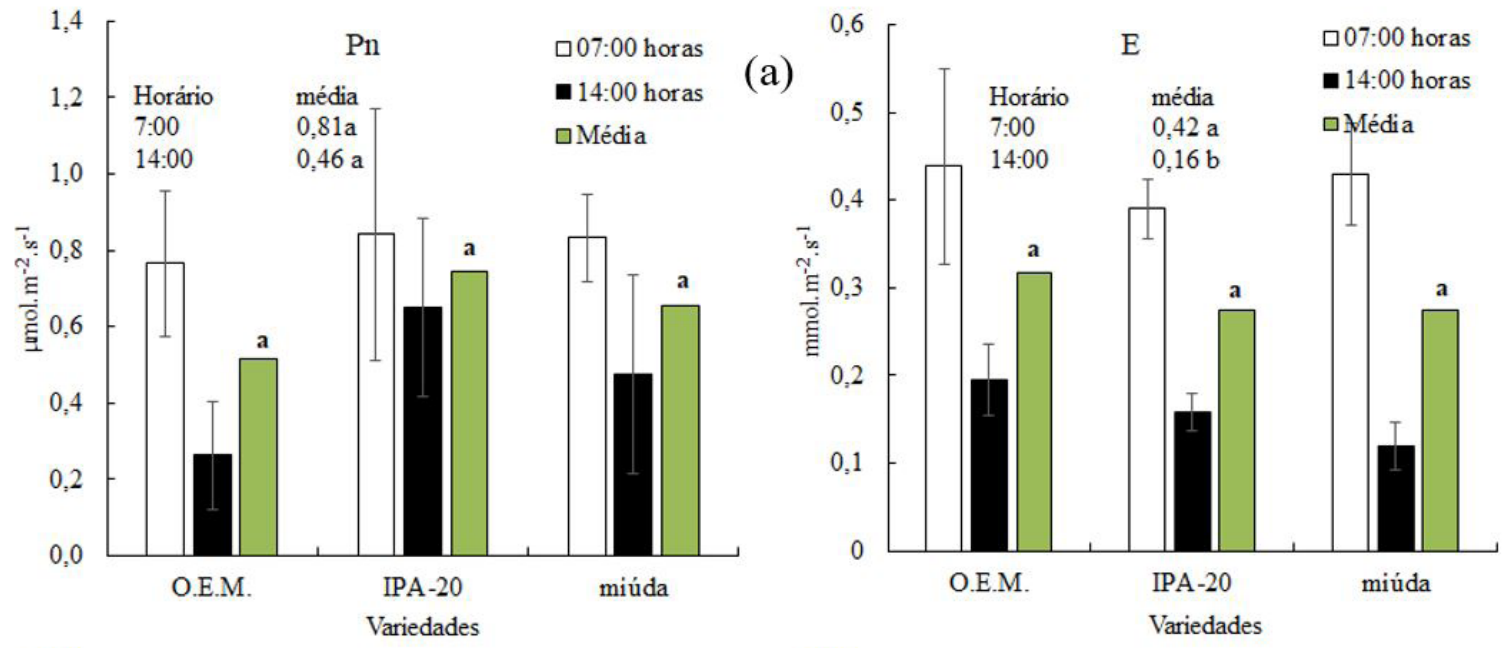

(b)
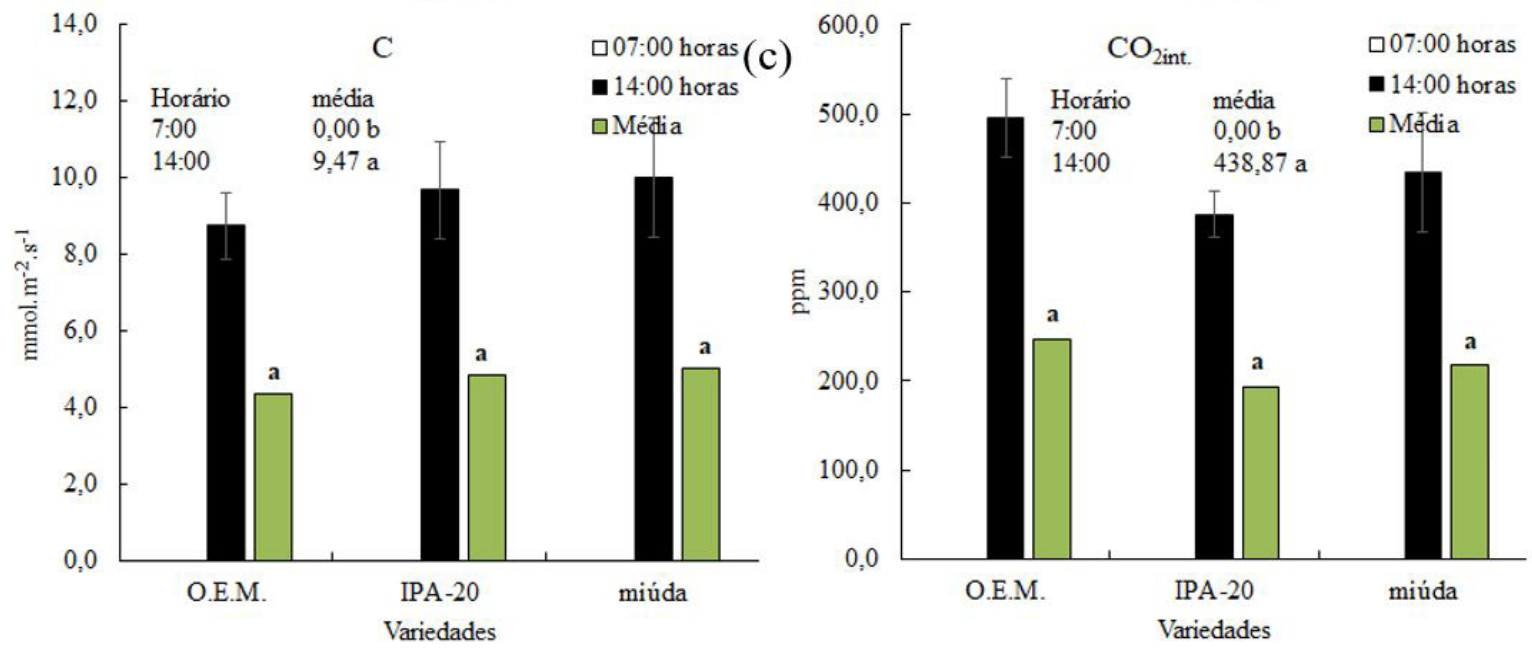

(d)

Figura 3. Taxa de assimilação líquida de $\mathrm{CO}_{2}-P n$ (a) taxa de transpiração - $E$ (b), taxa de condutância estomática - $C$ (c) e taxa de concentração interna de $\mathrm{CO}_{2}-\mathrm{CO}_{2 \text { int }}$ (d) nas variedades de palma forrageira Orelha de elefante mexicana - O.E.M. - IPA-200016, Clone IPA-20 - IPA-100003 e Miúda - IPA-100004, cultivadas em condições de telado, no município de Arcoverde-PE. As barras representam a média $(\mathrm{n}=6$ plantas $) \pm$ desvio padrão. Médias seguidas pela mesma letra não diferem entre si pelo teste de Tukey $(\mathrm{p}<0,05)$. 

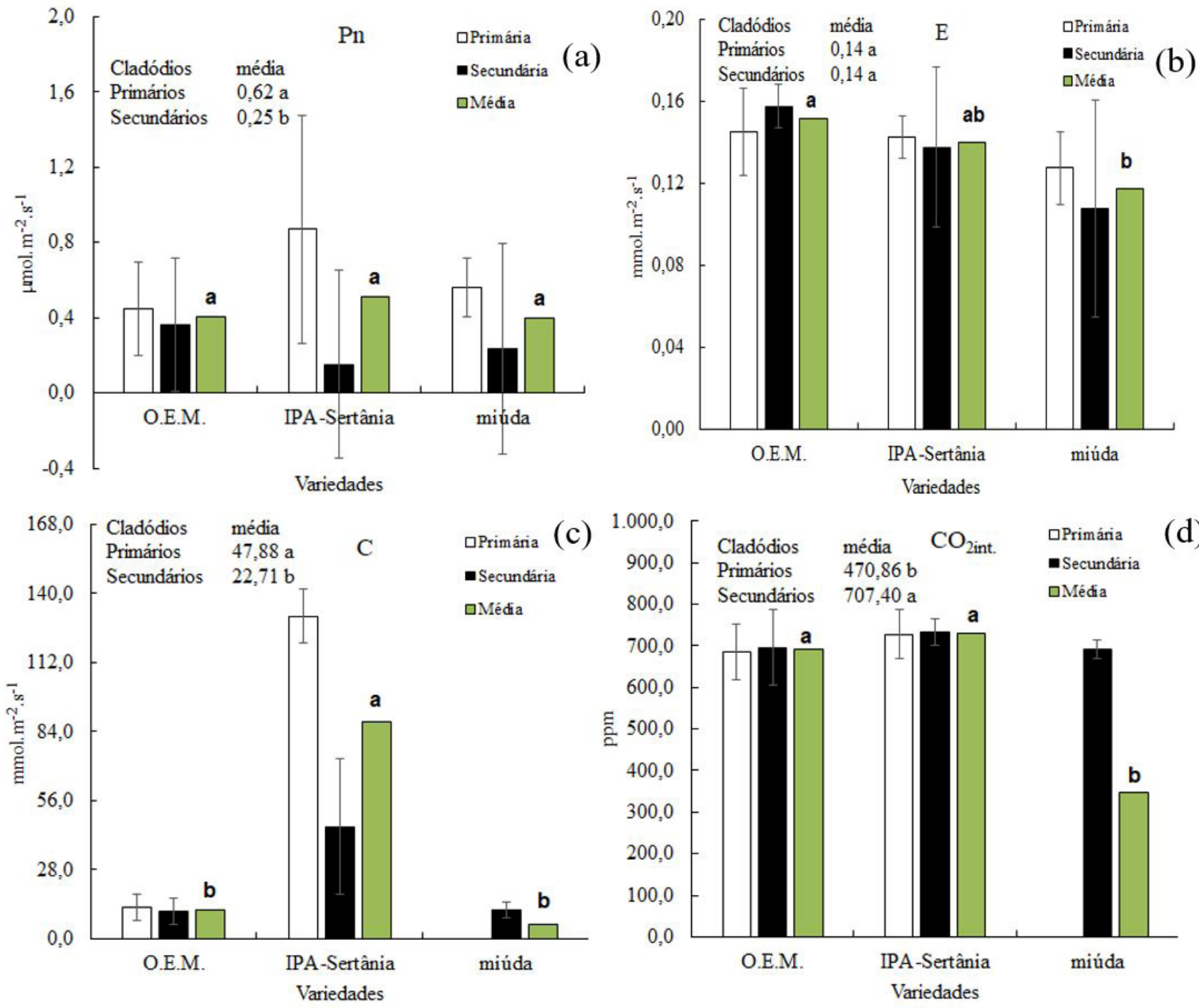

Figura 4. Taxa de assimilação líquida de $\mathrm{CO}_{2}-P n$ (a) taxa de transpiração - $E$ (b), taxa de condutância estomática - $C$ (c) e taxa de concentração interna de $\mathrm{CO}_{2}-\mathrm{CO}_{2 \text { int }}$ (d) nas variedades de palma forrageira Orelha de elefante mexicana - O.E.M. - IPA-200016, IPA-Sertânia - IPA-200205 e Miúda - IPA-100004, cultivadas em condições de sequeiro, no município de Ibimirim-PE. As barras representam a média ( $\mathrm{n}=6$ plantas) \pm desvio padrão. Médias seguidas pela mesma letra não diferem entre si pelo teste de Tukey $(\mathrm{p}<0,05)$.

Tabela 4. Análise de variância das características ambientais e fisiológicas da palma forrageira Clone IPA-20 - IPA-100003, cultivada no telado em condições de sequeiro e irrigada no município de Arcoverde-PE.

\begin{tabular}{|c|c|c|c|c|c|c|c|c|c|}
\hline \multirow{2}{*}{ Fonte de Variação } & \multicolumn{9}{|c|}{ Quadrado médio } \\
\hline & G.L & $\mathbf{T}_{\text {air }}$ & $\mathbf{T}_{\text {leaf }}$ & PAR & VPD & Pn & $\mathbf{E}$ & $\mathbf{C}$ & $\mathrm{CO}_{\text {2int. }}$ \\
\hline Bloco & 2 & $\mathbf{0 , 0 0 7}$ & 2,36 & 2747,25 & $\mathbf{0 , 0 0 7}$ & 0,864 & 0,0094 & 1,56 & 2924,21 \\
\hline Horário & 1 & $30,038 * *$ & $167,74 * *$ & $14619,93 n s$ & $19,099 * *$ & $0,617 \mathrm{~ns}$ & $0,0170 *$ & $525,56 * *$ & $76800,56 * *$ \\
\hline Cultivo & 1 & $86,070 * *$ & $66,83 * *$ & $1361,27 \mathrm{~ns}$ & $9,817 * *$ & $0,005 n s$ & $0,0010 \mathrm{~ns}$ & $1621,47 * *$ & $81941,06 * *$ \\
\hline Ordem cladódio & 1 & $0,210 \mathrm{~ns}$ & $0,90 \mathrm{~ns}$ & $36492,30 * *$ & $0,473 * *$ & $5,870 * *$ & $0,1504 * *$ & $1743,36 * *$ & $229468,14 * *$ \\
\hline Horário x Cultivo & 1 & $2,070 *$ & $8,82 \mathrm{~ns}$ & $50687,44 * *$ & $0,039 * *$ & $4,258 * *$ & $0,0032 n s$ & $1751,21 * *$ & $274423,01 * *$ \\
\hline Horário x Ordem cladódio & 1 & $0,210 \mathrm{~ns}$ & $0,33 n s$ & $2822,44 \mathrm{~ns}$ & $0,155^{* *}$ & $2,822 * *$ & $0,0013 n s$ & $1332,20 * *$ & $2095,33 n s$ \\
\hline Cultivo x Ordem cladódio & 1 & $0,683 n s$ & $3,96 \mathrm{~ns}$ & $19863,38 *$ & $0,710 * *$ & $6,355 * *$ & $0,0020 \mathrm{~ns}$ & $679,36 * *$ & $6920,70 \mathrm{~ns}$ \\
\hline Horário x Cultivo x Ordem cladódio & 1 & $1,020 \mathrm{~ns}$ & $0,008 n s$ & $12799,71 \mathrm{~ns}$ & $0,630 * *$ & $0,382 n s$ & $0,0088 n s$ & $615,19 * *$ & $138966,21 * *$ \\
\hline Resíduos & 14 & $\mathbf{0 , 3 8 8}$ & 2,42 & 4618,29 & 0,001 & 0,257 & 0,0026 & 1,56 & 1990,40 \\
\hline
\end{tabular}

$\mathrm{T}_{\text {air }}$ - temperatura do ar ambiente; $\mathrm{T}_{\text {leaf }}$ - temperatura dos cladódios; PAR - radiação fotossintética ativa; VPD - déficit de pressão de vapor; Pn - taxa de assimilação líquida de $\mathrm{CO}_{2}$; E - taxa de transpiração; $\mathrm{C}$ - taxa de condutância estomática; $\mathrm{CO}_{2 \text { int }}$ - taxa de concentração interna de $\mathrm{CO}_{2}$. ns não significativo; * significativo a $5 \%$; $* *$ significativo a $1 \%$ pelo teste $\mathrm{F}$. 
Tabela 5. Média das características ambientais e fisiológicas da palma forrageira Clone IPA-20 - IPA-100003, cultivada no telado em condições de sequeiro e irrigada no município de Arcoverde-PE.

\begin{tabular}{|c|c|c|c|c|c|c|c|c|c|}
\hline \multirow{2}{*}{\multicolumn{2}{|c|}{ Variáveis }} & \multicolumn{8}{|c|}{ Características } \\
\hline & & \multirow{2}{*}{$\frac{T_{\text {air }}}{32,63 \mathrm{~b}}$} & \multirow{2}{*}{$\frac{T_{\text {leaf }}}{31,72 \text { b }}$} & \multirow{2}{*}{$\begin{array}{c}\text { PAR } \\
198,21 \mathrm{a}\end{array}$} & \multirow{2}{*}{$\frac{\text { VPD }}{0,14 \text { b }}$} & \multirow{2}{*}{$\frac{\text { Pn }}{0,79 \text { a }}$} & \multirow{2}{*}{$\frac{E}{0,22 \text { b }}$} & \multirow{2}{*}{$\frac{C}{22,35 \text { a }}$} & \multirow{2}{*}{$\frac{\mathrm{CO}_{2 \text { int. }}}{312,91 \mathrm{~b}}$} \\
\hline Horário & 9:00 horas & & & & & & & & \\
\hline & 14:00 horas & 34,87 a & 37,01 a & 148,85 a & $1,93 \mathrm{a}$ & 0,47 a & 0,27 a & $12,99 \mathrm{~b}$ & 426,05 a \\
\hline \multirow[t]{2}{*}{ Cultivo } & Sequeiro & 35,65 a & 36,03 a & 181,06 a & $1,67 \mathrm{a}$ & 0,62 a & 0,25 a & 25,89 a & 427,91 a \\
\hline & Irrigado & 31,86 b & $32,70 \mathrm{~b}$ & 166,00 a & 0,39 b & 0,65 a & 0,24 a & 9,45 b & 311,05 b \\
\hline \multirow[t]{2}{*}{ Ordem } & Primário & 33,66 a & 34,17 a & $134,53 \mathrm{~b}$ & 1,17 a & $1,13 \mathrm{a}$ & 0,17 b & 9,14 b & $271,70 \mathrm{~b}$ \\
\hline & Broto & 33,85 a & 34,56 a & 212,52 a & 0,89 b & 0,14 b & 0,32 a & 26,19 a & 467,26 a \\
\hline
\end{tabular}

$\mathrm{T}_{\text {air }}$ - temperatura do ar ambiente; $\mathrm{T}_{\text {leaf }}$ - temperatura dos cladódios; PAR - radiação fotossintética ativa; VPD - déficit de pressão de vapor; Pn - taxa de assimilação líquida de $\mathrm{CO}_{2}$; E - taxa de transpiração; $\mathrm{C}$ - taxa de condutância estomática; $\mathrm{CO}_{2 \text { int }}$ - taxa de concentração interna de $\mathrm{CO}_{2}$. Médias seguidas pela mesma letra não diferem entre si pelo teste de Tukey $(\mathrm{p}<0,05)$.

danos ao aparelho fotossintético (TAIZ et al., 2017). A palma possui, em média, aproximadamente $94 \%$ de teor de água nos cladódios (ALVES et al., 2017), e, em média, a umidade do ambiente variou de $81,40 \%$ (tarde) a $86,51 \%$ (manhã), o que significa que a planta permaneceu com alto teor de umidade mesmo quando cultivada em condições de sequeiro (Figura 5).

$\mathrm{O}$ perfil das medidas registradas na variedade de palma Clone IPA-20 cultivadas em condições de sequeiro é diferente do obtido nas plantas cultivadas sob irrigação. As plantas cultivadas em condições de sequeiro não apresentam diferenças significativas entre a $T_{\text {air }}$ e $T_{\text {clad. }}$ nos horários avaliados ( 9 e 14 horas do dia). No entanto, as plantas cultivadas com complementação hídrica apresentaram $T_{\text {clad. }}$ menor que a $T_{\text {air }}$ nos cladódios primários às 9 horas e $T_{\text {clad }}$ maior que a $T_{\text {air }}$ nos cladódios jovens, ainda em crescimento, às 14 horas (Figura 5).

É importante mencionar que a umidade dentro - RHin e a umidade fora - RHout da câmara estomática não variam entre si ou entre as ordens dos cladódios. Entretanto, nos cladódios jovens a RHout. é sempre maior que a RHin, provavelmente por causa da alta transpiração desses cladódios. A umidade dentro e fora da câmara estomática é alta, acima de $80 \%$, nas plantas cultivadas em sequeiro e 100\% quando irrigadas (Figura 5). $\mathrm{O}$ aumento dessa umidade nas plantas irrigadas contribui para redução do $V P D, C$ e $C O_{\text {2int. }}$ (Figuras 5 e 6).

Não foram observadas diferenças significativas na $P n$ entre as plantas cultivadas em sequeiro ou irrigadas e entre os horários de avaliação (Figuras 6 e 7; Tabela 5). Entretanto, houve redução na $P n$ nos brotos (Tabela 5) e tendência a redução às 14 horas nas plantas irrigadas (Figura 7).

Não são detectadas diferenças significativas na $E$ entre as plantas cultivadas em condições de sequeiro ou irrigadas. No entanto, os valores tendem a serem maiores à tarde e nos cladódios mais jovens (Figura 6 e 7; Tabela 5). Observações de campo na cultura da palma revelam que os cladódios mais jovens são menos eficientes no controle da perda de água pela planta. As plantas de palma forrageira utilizam a perda de água como uma forma de reduzir a temperatura do cladódio nos períodos mais quentes do dia. Esses cladódios realizam suas trocas gasosas como se fossem plantas C3 (ALVES et al., 2020; DONATO; SILVA; DONATO, 2020). Essas plantas foram cultivadas em condições de telado com redução da luminosidade e a umidade relativa dentro e fora da câmara estomática estava alta $(>80 \%)$, condições essas que reduzem a perda de água e o déficit hídrico das plantas. Provavelmente esses cladódios não estavam sob déficit hídrico e não precisariam reduzir sua transpiração.

A $C$ e $C O_{2 i n t}$ às 9 horas são reduzidos significantemente quando as plantas são irrigadas (Figura 6). No entanto, às 14 horas não se observou diferença na $C$ entre as diferentes formas de cultivo (sequeiro e irrigada). Além do mais, nesse horário, as plantas irrigadas apresentaram superior $\mathrm{CO}_{\text {2int. }}$ quando comparadas às plantas cultivadas em condições de sequeiro (Figura 7). Mesmo sendo uma cultura de baixa necessidade hídrica, por apresentar o metabolismo ácido das crassuláceas, a palma forrageira melhora seus índices produtivos com a irrigação (SANTOS; SILVA, 2020). A menor $C O_{2 i n t}$ às 9 horas em comparação às 14 horas provavelmente está relacionada ao início da fotossíntese (DONATO; SILVA; DONATO, 2020).

Os resultados desse trabalho indicam que as variedades de palma forrageira avaliadas, independentemente de serem cultivadas em condições de sequeiro ou irrigadas, realizam suas trocas gasosas diurnas, contradizendo os relatos que plantas CAM somente fazem suas trocas gasosas à noite. Os valores médios diurnos referentes às taxas de assimilação líquida de $\mathrm{CO}_{2}$ - $P n$ nas variedades de palma forrageira variaram de $0,40 \mu \mathrm{mol} \cdot \mathrm{m}^{-2} \cdot \mathrm{s}^{-1}$ (Orelha de elefante mexicana e Miúda) a $0,75 \mu \mathrm{mol} \cdot \mathrm{m}^{-2} \cdot \mathrm{s}^{-1}$ (Clone IPA-20). A taxa de transpiração - $E$ variou de $0,12 \mathrm{mmol} \cdot \mathrm{m}^{-2} \cdot \mathrm{s}^{-1}$ (Miúda) a $0,32 \mathrm{mmol} \cdot \mathrm{m}^{-2} \cdot \mathrm{s}^{-1}$ (Orelha de elefante mexicana). A condutância estomática - $C$ variou de 4,36 $\mathrm{mmol} \cdot \mathrm{m}^{-2} \cdot \mathrm{s}^{-1}$ (Orelha de elefante mexicana) a $88,16 \mathrm{mmol} \cdot \mathrm{m}^{-2} \cdot \mathrm{s}^{-1}$ (IPA-Sertânia). A concentração interna de $\mathrm{CO}_{2}-\mathrm{CO}_{2 \text { int }}$ variou de 193,54 ppm (Clone IPA-20) a 731,08 ppm (IPA-Sertânia) (Figuras 3 e 4). Esses valores são compatíveis com os relatados em estudos anteriores realizados com a palma forrageira (ALVES et al., 2018a, 2018b; ALVES et al., 2020).

A taxa de assimilação de $\mathrm{CO}_{2}$ nas plantas $\mathrm{CAM}$ são divididas em 4 (quatro) fases ou períodos do dia: a fase I, corresponde ao período noturno; a fase II - começo da manhã; fase III - período diurno; e fase IV - final da tarde. Os relatos afirmam que as maiores taxas de assimilação de $\mathrm{CO}_{2}$ registradas nas plantas de palma forrageira acontecem durante a noite (fase I), diminuem no começo da manhã (fase II), chegando a valores mínimos ao meio-dia (fase III), e aumentam no final da tarde (fase IV), chegando a valores máximos à meia-noite (ALVES et al., 2018a, 2018b; LIGUORI et al., 2013; PIMIENTA-BARRIOS et al., 

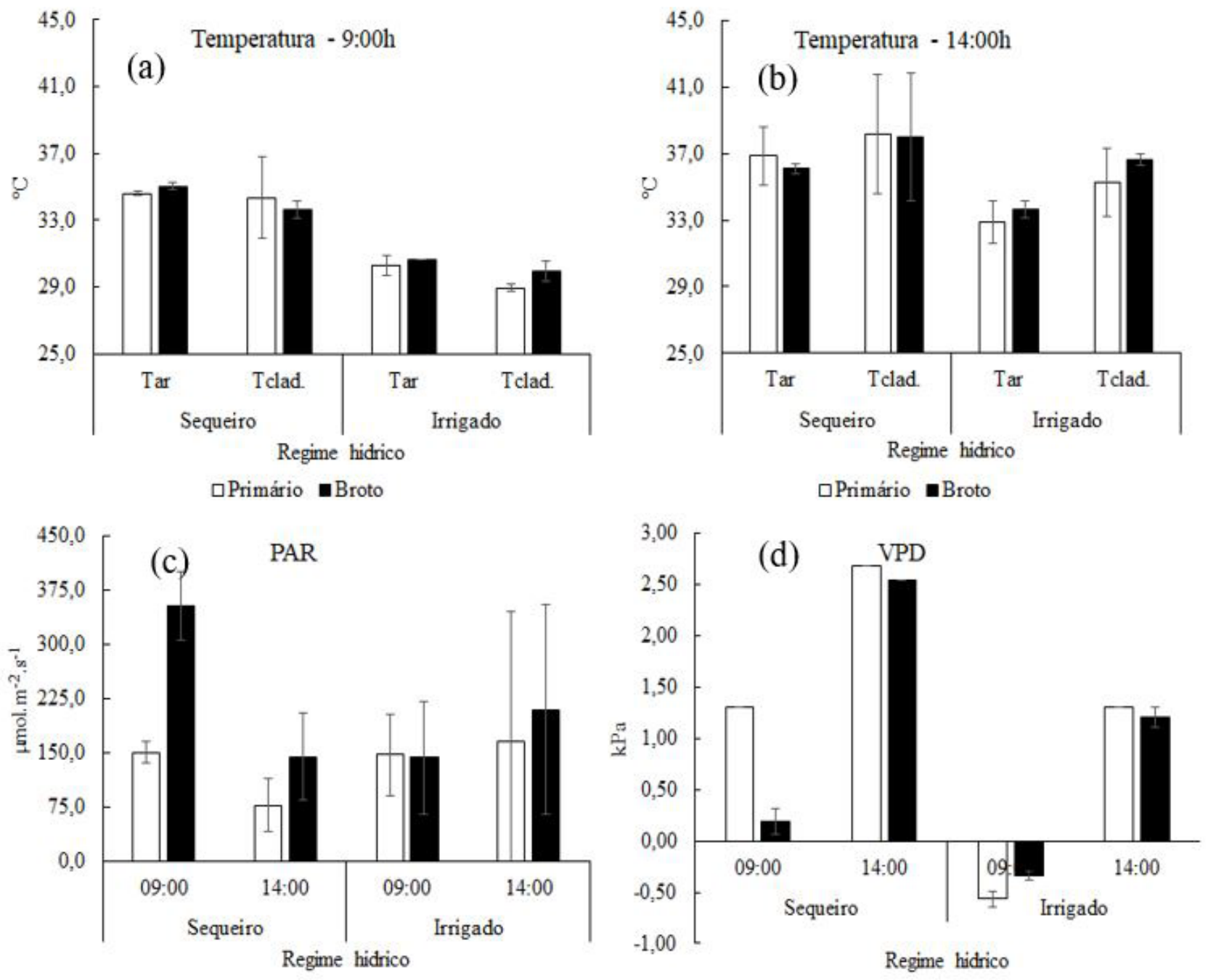

$\square$ Primário $\mathbf{m}$ Broto

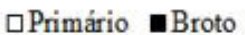
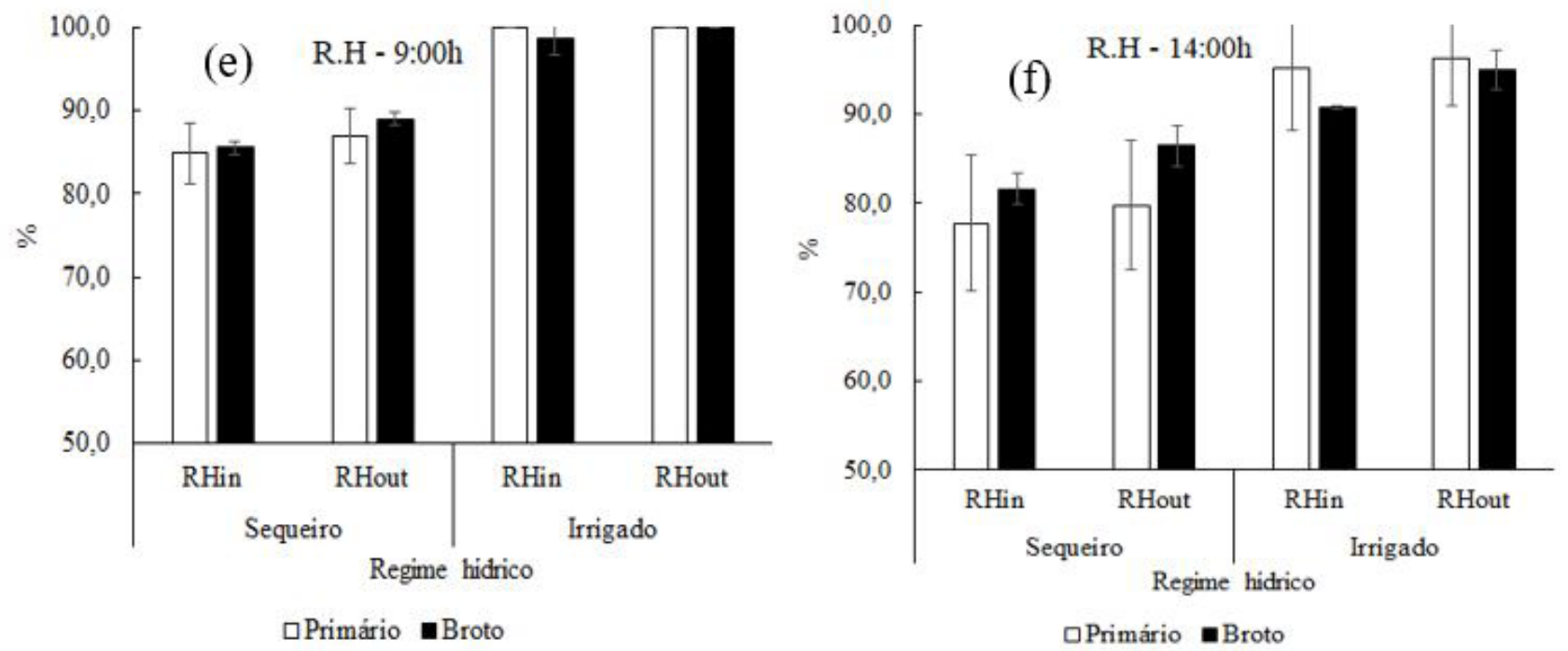

Figura 5. Temperatura do ar ambiente - $T_{\text {air }}$ e dos cladódios - $T_{\text {clad. }}$ às 9 horas (a) e às 14 horas (b), radiação fotossintética ativa - PAR (c), déficit de pressão de vapor - VPD (d) e umidade dentro - RHin e fora - RHout da câmara estomática às 9 horas (e) e às 14 horas (f) na palma forrageira Clone IPA-20 - IPA-100003, cultivada no telado em condições de sequeiro e irrigada, no município de Arcoverde-PE. As barras representam a média $(\mathrm{n}=6$ plantas $) \pm$ desvio padrão. 

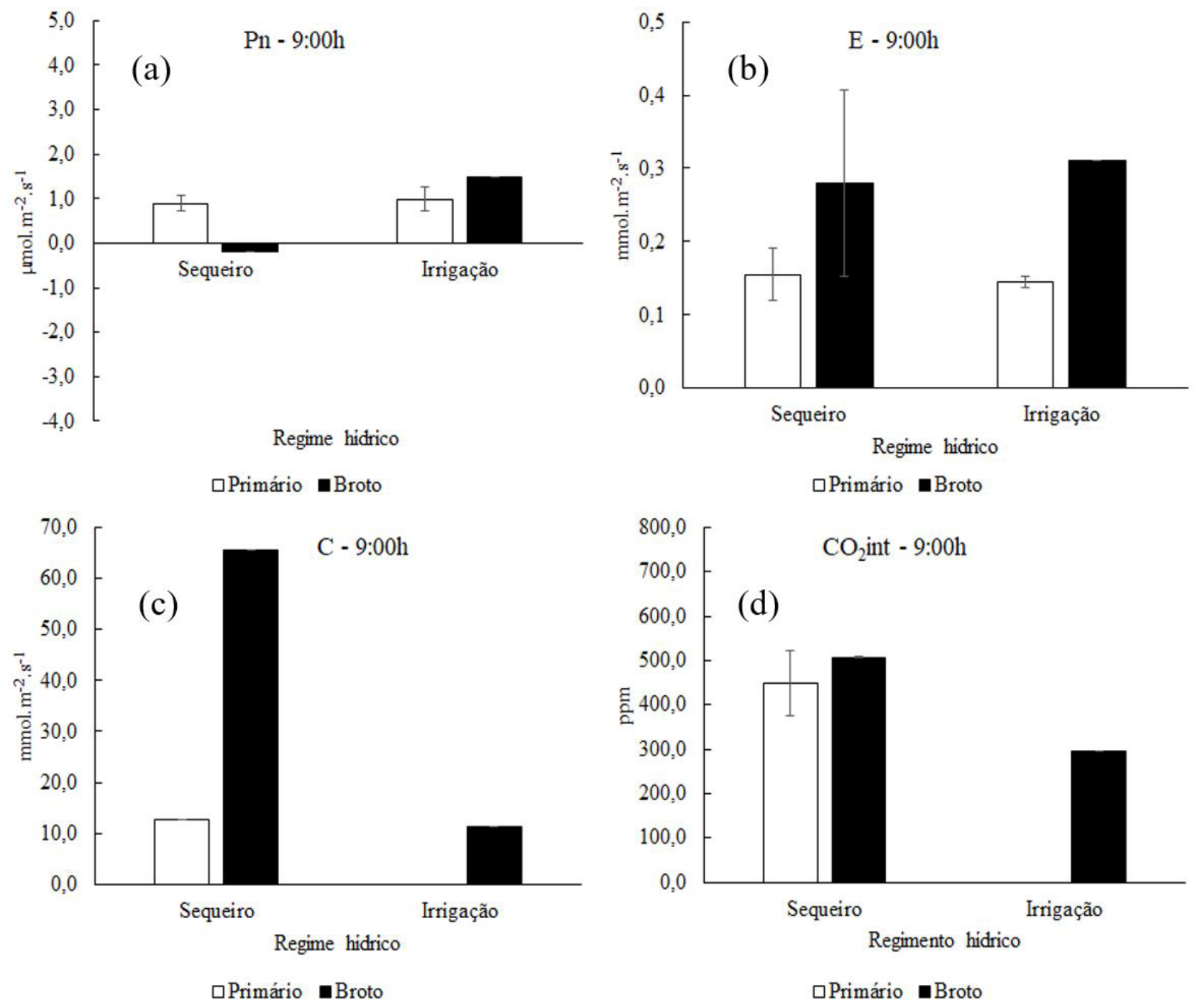

Figura 6. Taxa de assimilação líquida de $\mathrm{CO}_{2}-P n(\mathrm{a})$, taxa de transpiração - $E$ (b), taxa de condutância estomática - $C$ (c) e taxa de concentração interna de $\mathrm{CO}_{2}-\mathrm{CO}_{2 i n t}$ (d), às 9 horas, na palma forrageira Clone IPA-20 - IPA-100003, cultivada no telado em condições de sequeiro e irrigada, no município de Arcoverde-PE. As barras representam a média $(n=6$ plantas $) \pm$ desvio padrão.

2012; TAIZ et al., 2017). No entanto, mesmo com níveis bem reduzidos durante o dia (fase III) em comparação à noite, a taxa de assimilação de $\mathrm{CO}_{2}$ na palma forrageira continua a ocorrer com valores positivos.

Além disso, os resultados demonstram que as plantas de palma forrageira transpiram durante o dia (ALVES et al., 2018a,b; ALVES et al., 2020; GERWICK; WILLIAMS, 1978; WHITING; CAMPBELL, 1984). No entanto, os valores são bem inferiores aos encontrados em plantas $\mathrm{C}_{3}$ e $\mathrm{C}_{4}$, indicando a alta eficiência no uso da água dessas plantas (RIBEIRO et al., 2012; SILVA et al., 2019; SOUSA et al., 2012).

O padrão de condutância estomática observado nesse trabalho é idêntico aos relatados para plantas $\mathrm{C}_{3}$ e $\mathrm{C}_{4}$, em que durante o dia a condutância é positiva (TAIZ et al., 2017). Entretanto, os valores são bem inferiores ao relatados para plantas $\mathrm{C}_{3} \mathrm{e}_{4}$.

A não detecção de condutância estomática no começo da manhã nas variedades de palma (Figuras 3 e 4), provavelmente se deve a não variação da perda de água e/ou não variação na abertura dos estômatos durante as medições, tendo em vista que a umidade do ar dentro e fora da câmara estomática era de $100 \%$. Inclusive a variação na pressão de vapor de água - VPD verificada neste horário foi negativa (Figuras 1 e 2).

A condutância estomática é influenciada pelas condições atmosféricas, ou seja, se há mais vapor de água na atmosfera, diminui-se o déficit de pressão de vapor e, consequentemente, diminui-se a condutância estomática e vice-versa (RODRIGUES et al., 2011).

No que se refere à concentração interna de $\mathrm{CO}_{2}$, esta se apresenta intimamente relacionada com a condutância estomática. Assim, a não detecção da condutância estomática nas variedades de palma também reflete na concentração interna de $\mathrm{CO}_{2}$ (Figuras 3 e 4). Por sua vez, a elevada concentração interna de $\mathrm{CO}_{2}$ induz ao fechamento estomático parcial e, consequentemente, à redução na transpiração (LUTTGE, 2004).

A $\mathrm{CO}_{2 \text { int. }}$ foi verificada pela manhã e à tarde nas variedades de palma forrageira estudadas. Esse padrão coincide com o ciclo de carboxilação diário. Durante a noite, o $\mathrm{CO}_{2}$ atmosférico e respiratório é fixado em malato, que é estocado e descarboxilado durante o dia para entrar no ciclo de Calvin 

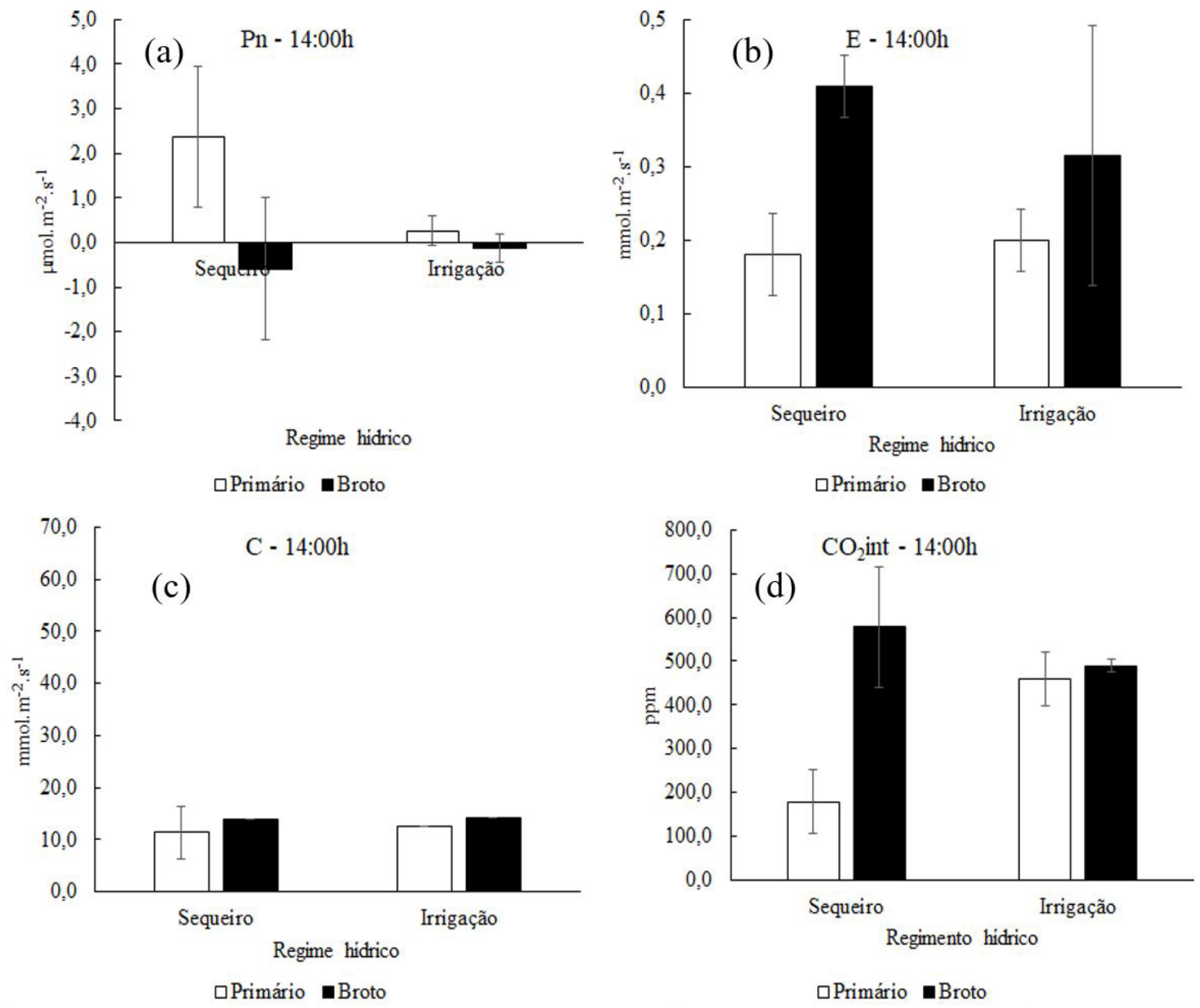

Figura 7. Taxa de assimilação líquida de $\mathrm{CO}_{2}-P n$ (a), taxa de transpiração - $E$ (b), taxa de condutância estomática - $C$ (c) e taxa de concentração interna de $\mathrm{CO}_{2}-\mathrm{CO}_{2 i n t}$ (d), às 14 horas, na palma forrageira Clone IPA-20 - IPA-100003, cultivada no telado em condições de sequeiro e irrigada, no município de Arcoverde-PE. As barras representam a média $(\mathrm{n}=6$ plantas $) \pm$ desvio padrão.

(PIMIENTA-BARRIOS; ZAÑUDO-HERNÁNDEZ; NOBEL, 2005; PIMIENTA-BARRIOS et al., 2005; TAIZ et al., 2017). Ademais, pequena assimilação de $\mathrm{CO}_{2}$ é detectada durante o dia, quando os estômatos estão abertos, contribuindo para o pool de $\mathrm{CO}_{2}$ no sítio ativo da rubisco (LUTTGE, 2004).

Diante destes resultados e considerando que as maiores taxas de assimilação líquida de $\mathrm{CO}_{2}$ ocorrem à noite (modo CAM) nas espécies de Opuntia e Nopalea, a constatação de trocas gasosas durante o dia possibilita caracterizar as principais variedades de palma forrageira cultivadas no Brasil como plantas do grupo fotossintético CAM-facultativo. Estudos anteriores mostraram que à noite seus estômatos estavam fechados, mesmo assim, as maiores taxas de assimilação de $\mathrm{CO}_{2}$ aconteceram nesse período (fase I), provavelmente por uma recirculação interna do $\mathrm{CO}_{2}$ respiratório. De fato, observou-se que os cladódios das plantas de palma forrageira das variedades IPA-Sertânia e Orelha de Elefante Mexicana podem sobreviver por mais de seis meses após a colheita, quando armazenadas na sombra em temperatura ambiente (dados não publicados). Durante o dia (fases II, III e IV) com os estômatos abertos é detectada pequena assimilação de $\mathrm{CO}_{2}$ e transpiração. Ademais, verifica-se uma grande concentração interna de $\mathrm{CO}_{2}$ durante esse período, provavelmente pela descarboxilação do malato acumulado à noite e assimilação de $\mathrm{CO}_{2}$ do ambiente (ALVES et al., 2018a,b).

\section{Considerações Finais}

As variedades de palma forrageira Orelha de elefante mexicana IPA-200016, Clone IPA-20 - IPA-100003, IPA-Sertânia IPA-200205 e Miúda - IPA-100004, consideradas até o momento como plantas do grupo fotossintético CAM-obrigatórias, também realizam trocas gasosas (assimilação de $\mathrm{CO}_{2}$ e perda de $\mathrm{H}_{2} \mathrm{O}$ ) durante o dia (7:00, 9:00 e 14:00 horas), cultivadas com ou sem irrigação.

Diante destes resultados e considerando que em estudos anteriores foi descrito que nas espécies de Opuntia e Nopalea, as maiores taxas de assimilação líquida de $\mathrm{CO}_{2}$ ocorrem à noite (modo CAM-obrigatória), a constatação de trocas gasosas 
durante o dia possibilitam caracterizar as principais variedades de palma forrageira cultivadas no Brasil como plantas do grupo fotossintético CAM-facultativo.

\section{Agradecimentos}

Os autores agradecem ao IPA e a Secretaria de Agricultura e Desenvolvimento Agrário do Estado de Pernambuco pelo suporte financeiro para a realização desta pesquisa.

\section{Referências}

ALVES, F. A. L. et al. Chemical and nutritional variability of cactus pear cladodes, genera Opuntia and Nopalea. American Journal of Food Technology, New York, v. 12, n. 1, p. 25-34, 2017

ALVES, F. A. L. et al. Study of the genetic variability, correlation and importance of phenotypic characteristics in cactus pear (Opuntia and Nopalea). African Journal of Agricultural Research, Kenya, v. 11, n. 31, p. 2849-2859, 2016.

ALVES, F. A. L. et al. Trocas gasosas e eficiência no uso da água de palma forrageira (Opuntia stricta) cultivadas em telado sob irrigação. In: SIMPÓSIO NACIONAL DE ESTUDOS PARA PRODUÇÃO VEGETAL NO SEMIÁRIDO, 3., 2018, Campina Grande. Anais... Campina Grande: SIMPROVS, 2018a. Disponível em: <http://www.editorarealize.com.br/revistas/sinprovs/trabalhos/ TRABALHO EV105 MD4 SA4 ID163 29032018163813.pdf>. Acesso em: 8 jun. 2020 .

ALVES, F. A. L. et al. Variabilidade das trocas gasosas entre cladódios de palma forrageira (Nopalea cochenillifera) cultivadas em telado sob irrigação. In: SIMPÓSIO NACIONAL DE ESTUDOS PARA PRODUÇÃO VEGETAL NO SEMIÁRIDO, 3., 2018, Campina Grande. Anais... Campina Grande: SIMPROVS, 2018b. Disponível em: <http://www.editorarealize.com.br/revistas/sinprovs/trabalhos/ TRABALHO_EV105 MD1_SA2 ID163 29032018162933.pdf> Acesso em: 8 jun. 2020.

ALVES, F. A. L. et al. Photosynthesis and gas exchanges of forage cactus varieties (Opuntia and Nopalea) grown under screen and irrigation. Pesquisa Agropecuária Pernambucana, Recife, v. 25, n. 1, p. 1-15, 2020.

BUCKLEY, T. N. Modeling stomatal conductance. Plant Physiology, Minneapolis, v. 174, n. 2, p. 572-582, 2017. http://dx.doi.org/10.1104/ pp.16.01772.

DONATO, S. M.; SILVA, J. A.; DONATO, P. E. R. Aspectos ecofisiológicos. In: DONATO, S. L. R.; BORÉM, A.; RODRIGUES, M. G. V. Palma forrageira do plantio à colheita. 1. ed. Belo Horizonte: EPAMIG, 2020. cap. 3, p. 43-77.

FERREIRA, D. F. SISVAR: a computer analysis system to fixed effects split plot type designs. Revista Brasileira de Biometria, Lavras, v. 37, n. 4, p. 529-535, 2019.

GERWICK, B. C.; WILLIAMS, G. J. Temperature and water regulation of gas exchange of Opuntia polyacantha. Oecologia, New York, v. 35, n. 2 , p. $149-159,1978$.

GÓMEZ, J. M. R. et al. A irradiância solar: conceitos básicos. Revista Brasileira de Ensino de Física, São Paulo, v. 40, n. 3, p. e3312, 2018.

INSTITUTO BRASILEIRO DE GEOGRAFIA E ESTATISTICA IBGE. Censo agropecuário 2017. Rio de Janeiro, 2017. Disponível em: $<$ https://sidra.ibge.gov.br/tabela/6615\#resultado $>$. Acesso em: 19 set. 2019.

LIGUORI, G. et al. $\mathrm{CO}_{2}$ uptake of Opuntia ficus-indica (L.) Mill. whole trees and single cladodes, in relation to plant water status and cladode age. Italian Journal of Agronomy, Italy, v. 8, n. 3, p. $14-20,2013$

LIRA-JÚNIOR, J. S. et al. Compostos antioxidantes em frutos de acessos de caramboleira em diferentes ambientes de Pernambuco. Revista Brasileira de Fruticultura, Cruz das Almas, v. 36, n. 4, p. 813-819, 2014.

LUTTGE, U. Ecophysiology of Crassulacean Acid Metabolism (CAM). Annals of Botany, Oxford, v. 93, n. 6, p. 629-652, 2004

NUNES-FILHO, J.N. et al. Gramíneas forrageiras tropicais em solo salino-sódico, sob irrigação, no Vale do Rio Moxotó - Pernambuco. Pesquisa Agropecuária Pernambucana, Recife, v.14, n.especial, p.19-24, 2008.

OLIVEIRA, F. T. et al. Palma forrageira: Adaptação e importância para os ecossistemas áridos e semiáridos. Revista Verde de Agroecologia e Desenvolvimento Sustentável, Pombal, v. 5, n. 4, p. 27-37, 2010.

PIMIENTA-BARRIOS, E. et al. Ecophysiology of young stems (cladodes) of Opuntia ficus-indica in wet and dry conditions. Gayana. Botánica, Concepcion, v. 69, n. 2, p. 232-239, 2012.

PIMIENTA-BARRIOS, E. et al. Young daughter cladodes affect $\mathrm{CO}_{2}$ uptake by mother cladodes of Opuntia ficus-indica. Annals of Botany, Oxford, , v. 95, n. 2, p. 363-369, 2005.

PIMIENTA-BARRIOS, E.; ZAÑUDO-HERNÁNDEZ, J.; NOBEL, P. $\mathrm{S}$. Effects of young cladodes on the gas exchange of basal cladodes of Opuntia ficus-indica (cactaceae) under wet and dry conditions. International Journal of Plant Sciences, Chicago, v. 166, n. 6, p. 961-968, 2005.

RIBEIRO, R. V. et al. Moderate warm temperature improves shoot growth, affects carbohydrate status and stimulates photosynthesis of sweet orange plants. Brazilian Journal of Plant Physiology, Londrina, v. 24, n. 1, p. 37-46, 2012.

RODRIGUES, H. J. B. et al. Variabilidade sazonal da condutância estomática em um ecossistema de manguezal amazônico e suas relações com variáveis meteorológicas. Revista Brasileira de Meteorologia, São José dos Campos, v. 26, n. 2, p. 189-196, 2011.

SANTOS, M. R.; SILVA, A. J. P. Irrigação. In: DONATO, S. L. R.; BORÉM, A.; RODRIGUES, M. G. V. Palma forrageira do plantio à colheita. 1. ed. Belo Horizonte: EPAMIG, 2020. cap. 7, p. 151-173.

SILVA, L. K. S. et al. Gas exchange and photochemical efficiency of Caatinga plants submitted to different water management strategies. The Journal of Agricultural Science, Cambridge, v. 11, n. 11, p. 53-69, 2019.

SOUSA, A. E. C. et al. Trocas gasosas e conteúdo de carboidratos e compostos nitrogenados em pinhão-manso irrigado com águas residuária e salina. Pesquisa Agropecuária Brasileira, Brasília, v. 47, n. 10, p. 1428-1435, 2012.

SOUSA, A. R. et al. Descrição e interpretação do perfil de um Neossolo Regolítico Eutrófico solódico do Agreste pernambucano. Pesquisa Agropecuária Pernambucana, Recife, v. 16, p. 64-73, 2011

TAIZ, L. et al. Fisiologia e desenvolvimento vegetal. 6. ed. Porto Alegre: Artmed, 2017. 858 p.

WHITING, B. H.; CAMPBELL, E. E. Effect of moisture supply on CAM in Opuntia aurantiaca (jointed cactus). South African Journal of Plant and Soil, Pretoria, v. 1, n. 3, p. 87-91, 1984. 